\title{
Timing of High Temperature Influences Chilling Negation in Dormant Apple Trees
}

\author{
Eric Young \\ Department of Horticultural Science, North Carolina State Universiy, Box 7609, Raleigh, \\ NC 27695 \\ Additional index words. Malus domestics, budbreak, root growth
}

\begin{abstract}
Budbreak and root and shoot extension growth of apple trees (Malus domestics Borkh. MM.111) were affected by exposure to 500 hours of higher temperatures $(15,20$, or $30 \mathrm{C})$ during the first, second, or third 500 hours of a 1500-hour, 5C chilling period. Exposure to 15C during the third 500 hours had a significantly positive effect on budbreak, 20C at this time had no effect, and all other treatments had a negative effect on budbreak and new root and shoot growth.
\end{abstract}

A negative accumulation factor was included in the tree fruit chilling model developed by Richardson et al. (1974) for temperatures $>14 \mathrm{C}$ because they found that exposure to temperatures above this point reversed the chilling effects. Since then the negation of chilling by high temperatures has been studied in detail for peach [Prunus persica (L.) Batsch.]. It has been demonstrated that 8-h interruptions at $24 \mathrm{C}$ with $16 \mathrm{~h}$ at $6 \mathrm{C}$ resulted in complete negation of chilling in peach (Erez et al., 1979a). Also, they found that the high-temperature interruption had to exceed $4 \mathrm{~h}$ to have a negating effect (Couvillon and Erez, 1985), and the negation by high temperature only occurred during the first two-thirds of the chilling period (Couvillon and Erez, 1985). However, I found no work describing chilling negation by high temperatures in apple, either related to temperature or timing. In addition, because new root growth in apple is enhanced by chilling (Young and Werner, 1985 b), high-temperature interruptions may also have an effect on root growth. The study described here was done to determine the effectiveness of various temperatures and of timing on high-temperature negation of chilling and its effect on apple budbreak and growth of new shoots and roots.

\section{Materials and Methods}

One-year-old rooted layers of apple were lifted from a commercial stool bed after $<100 \mathrm{CU}$ (Richardson et al., 1974) in fall. Chilling requirement for MM. 111 has been reported by Young and Werner (1985a) as 1450 CU for $90 \%$ budbreak and by Hauagge and Cummins (1991) as 1419 CU. Trees were pruned to $30 \mathrm{~cm}$ and potted in 3.5-liter containers in calcined clay and placed in- growth chambers under 8-h photoperiods for various temperature treatments. Temperature treatments were given in three 500-h increments according to the following schedules: $\mathrm{T}-5 \mathrm{C}-5 \mathrm{C}, 5 \mathrm{C}-\mathrm{T}-5 \mathrm{C}$, or $5 \mathrm{C}-5 \mathrm{C}-\mathrm{T}$, where $\mathrm{T}=5,15,20$, or $30 \pm 1 \mathrm{C}$. The 5-5-5C treatment was considered to be the control. After $1500 \mathrm{~h}$ total, trees were moved to a growth chamber at $20 \pm 1 \mathrm{C}$ and 18-h photoperiod for forcing. During forcing, budbreak was counted at 3-day intervals and percent budbreak calculated as percent of treatment with maximum budbreak. After 21 days, trees were harvested and new, unsuberized root growth was rated as described by Young and Werner (1990; $1=$ no new roots, $3=$ new root growth on about half the old

Received for publication 31 May 1990. Accepted for publication 12 Nov. 1991. The research reported in this publication was funded by the North Carolina Agricultural Research Service. The cost of publishing this paper was defrayed in part by the payment of page charges. Under postal regulations, this paper therefore must be hereby marked advertisement solely to indicate this fact. root system, $5=$ new roots throughout the old root system). Also, new shoot extension growth was weighed after being dried.

The design was a randomized complete block with 10 singletree replications. Budbreak and shoot and root measurements were analyzed as a $4 \times 3$ factorial with four temperatures and three time intervals. Percent budbreak was subjected to arcsin transformation before analysis and a pooled SE of the mean was calculated for each temperature treatment over the three time intervals. Shoot dry weight and root rating means were separated by Tukey's least significant difference test.

\section{Results and Discussion}

Trees receiving 15 or $20 \mathrm{C}$ during the first or second $500 \mathrm{~h}$ of chilling had significantly less budbreak (Figs. 1-3) and new shoot and root growth (Figs. 4 and 5) than those under continuous 5C. Root growth was decreased more by $20 \mathrm{C}$ than by $15 \mathrm{C}$ (Fig. 5). Budbreak was increased, and new shoot and root growth were unaffected on trees receiving $15 \mathrm{C}$ during the last $500 \mathrm{~h}$ of the chilling period (Figs. 1, 4, and 5). Trees receiving 20C during this time showed no change in budbreak, but had decreased new shoot and root growth (Figs. 2, 4, and 5). When trees received $30 \mathrm{C}$ at any time during chilling, all variables were decreased relative to trees exposed to lower temperatures (Figs. 3-5). These results generally agree with those reported for peach budbreak (Couvillon and Erez, 1985). High temperatures before any chilling had a significant negative effect on subsequent chilling accumulation (Figs. 1-3). In fact, exposure to 30C before chilling had a greater effect than when given as an interruption of chilling (Fig. 3). Couvillon and Erez (1985) did not test exposure to high temperatures before low-temperature exposure.

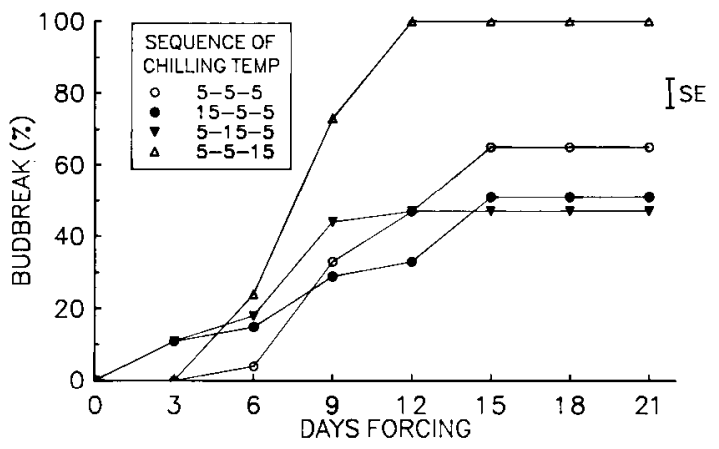

Fig. 1. Budbreak sequence of MM.111 apple trees during forcing at $20 \mathrm{C}$ after they had received temperature treatments at 500-h intervals during a 1500-h chilling period according to the following sequences: $15-5-5 \mathrm{C}$; $5-15-5 \mathrm{C}$; $5-5-15 \mathrm{C}$; or $5-5-5 \mathrm{C}$ (control) for $1500 \mathrm{~h}$. SE indicates the pooled SE of the means, $\mathrm{n}=10$. 


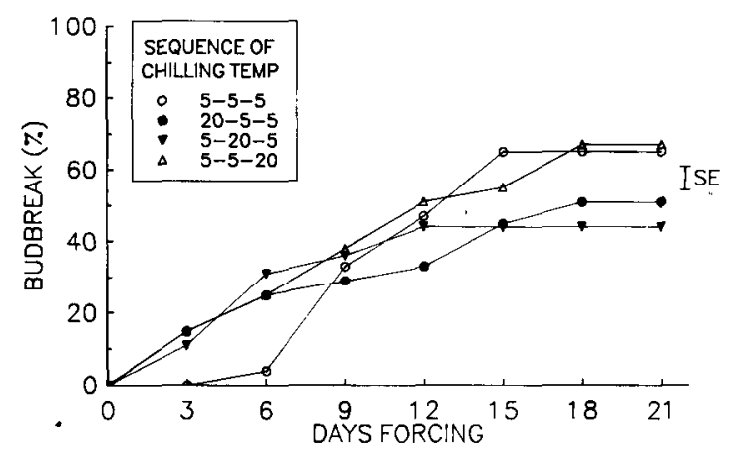

Fig. 2. Budbreak sequence ofMM.111 apple trees during forcing at $20 \mathrm{C}$ after they had received temperature treatments at 500-h intervals during a 1500-h chilling period according to the following sequences: $20-5-5 \mathrm{C}$; 5-20-5C; $5-5-20 \mathrm{C}$; or 5-5-5C (control) for $1500 \mathrm{~h}$. SE indicates the pooled $\mathrm{SE}$ of the means, $\mathrm{n}=10$.

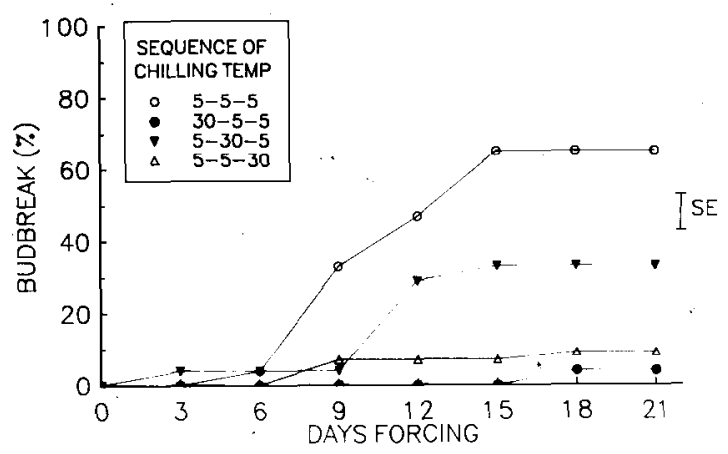

Fig. 3. Budbreak sequence of MM. 111 apple trees during forcing at $20 \mathrm{C}$ after they had received temperature treatments at 500-h intervals during a 1500-h chilling period according to the following sequences: $30-5-5 \mathrm{C}$; 5-30-5C; 5-5-30C; or 5-5-5C (control) for $1500 \mathrm{~h}$. SE indicates the pooled SE of the means, $\mathrm{n}=10$.

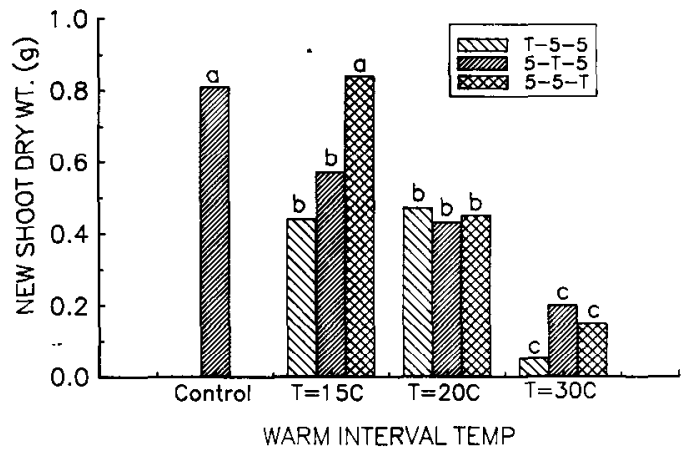

Fig. 4. New shoot dry weight of MM.111 apple trees after being forced for 21 days at $20 \mathrm{C}$ after having received high-temperature treatments at various times during chilling. Control trees were continuously at $5 \mathrm{C}$ during the chilling period. Mean separation by Tukey's least significant difference test, $P=0.05, \mathrm{n}=10$.

Exposing the trees to $15 \mathrm{C}$ after they had received $1000 \mathrm{CU}$ enhanced budbreak (Fig. 1), but budbreak of those trees exposed to $20 \mathrm{C}$ after $1000 \mathrm{CU}$ was similar to the continuously chilled controls (Fig. 2). This result was unexpected based on the peach chilling model of Richardson et al. (1974), which indicated that the $15 \mathrm{C}$ treatment should not have contributed CU. Therefore,

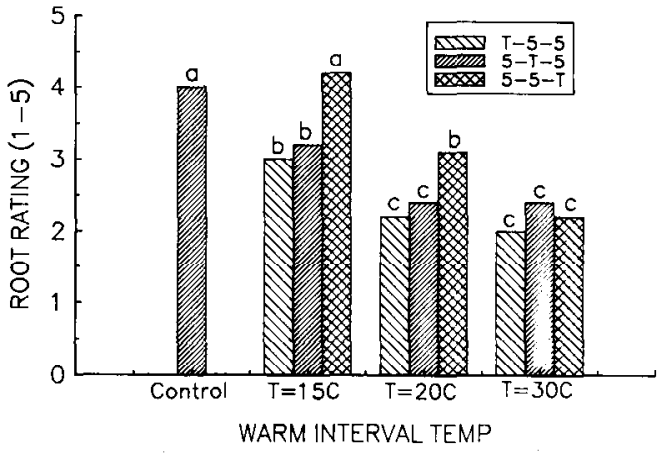

Fig. 5. Relative amount of new root growth expressed as root rating $(1=$ no new roots, $5=$ new roots throughout the old root system $)$ of MM.111 apple trees after being forced for 21 days at 20C after having received high-temperature treatments at various times during chilling. Control trees were continuously at 5C-during the chilling period. Mean separation by Tukey's least significant difference test, $P=0.05, \mathrm{n}=10$.

these trees should lack 420 to $450 \mathrm{CU}$. The $20 \mathrm{C}$ treatment should have contributed - $1 \mathrm{CU}$; thus, these trees would have accumulated $500 \mathrm{CU}, 920$ to $950 \mathrm{CU}$ fewer than necessary for full chilling. Based on the peach chilling model, budbreak of trees receiving $15 \mathrm{C}$ after $1000 \mathrm{CU}$ should have been slightly less than the controls, and those receiving $20 \mathrm{C}$ should have had decidedly delayed and reduced budbreak. Apparently, the contribution of higher temperatures toward chilling changes as chilling progresses, resulting in a slightly higher temperature (15C) late in dormancy having a positive effect and $20 \mathrm{C}$ at this time not having the negating effect that the model predicts. The budbreak-enhancing effect of $15 \mathrm{C}$ cannot be due to heat accumulation because $20 \mathrm{C}$ did not have the same effect. Therefore, these results indicate that there is a slight upward shift in optimum chilling temperature toward the latter stages of chilling. Erez et al. (1979b) found that $8 \mathrm{~h}$ of $15 \mathrm{C}$ alternated with $16 \mathrm{~h}$ of $6 \mathrm{C}$ was more efficient than continuous chilling at $6 \mathrm{C}$ in breaking bud dormancy of peach trees. The results reported here indicate that a continuous $15 \mathrm{C}$ during the later portion of the chilling period has a similar effect on apple budbreak.

New shoot and root growth were reduced more than budbreak by the 20C treatments (Figs. 4 and 5), particularly when given during the last third of the chilling cycle. Also, 30C during chilling had a greater negative effect on new shoot growth than new root growth.

The transition period from chilling accumulation to growingdegree hour accumulation has not been well studied relative to optimum temperatures. It appears from the results reported here that temperatures 5 to $10 \mathrm{C}$ higher than those usually considered optimum for chilling may accelerate the progression toward budbreak if they occur after a significant portion of the chilling requirement has been received. This result implies that in winters when temperatures rise earlier than normal and calculated $\mathrm{CU}$ indicate most apple cultivars are somewhat underchilled, budbreak is likely to proceed normally, and abnormalities due to underchilling probably will not occur. This situation occurred in the winter of 1988-89, when temperatures remained > 10C in western North Carolina after $\approx 1000 \mathrm{CU}$ had been received. Observations indicated that vegetative and flower budbreak were not reduced or delayed and none of the symptoms of insufficient chilling, such as small leaves or malformed flowers, were evident. 


\section{Literature Cited}

Couvillon, G.A. and A. Erez. 1985. Effect of level and duration of high temperatures on rest in the peach. J. Amer. Soc. Hort. Sci. 110:579-581.

Erez, A., G.A. Couvillon, and C.H. Hendershott. 1979a. The effect of cycle length on chilling negation by high temperatures in dormant peach leaf buds. J. Amer. Soc. Hort. Sci. 104:573-576.

Erez, A., G.A. Couvillon, and C.H. Hendershott. 1979b. Quantitative chilling enhancement and negation in peach buds by high temperatures in a daily cycle. J. Amer. Soc. Hort. Sci. 104:536-540.

Hauagge, R. and J.N. Cummins. 1991. Phenotypic variation of length of bud dormancy in apple cultivars and related Malus species. J. Amer. Soc. Hort. Sci. 116:100-106.
Richardson, E.A., S.D. Seeley, and D.R. Walker. 1974. A model for estimating the completion of rest for 'Redhaven' and 'Elberta' peach trees. HortScience 9:331-332.

Young, E. and D.J. Werner. 1985a. Chill unit and growing degree hour requirements for vegetative bud break in six apple rootstock. J. Amer. Soc. Hort. Sci. 110:411-413.

Young, E. and D.J. Werner. 1985b. Effects of shoot, root, and shank chilling during rest in apple and peach on growth resumption and carbohydrates. J. Amer. Soc. Hort. Sci. 110:769-774.

Young, E. and D.J. Werner. 1990. Changes in respiration rate and energy of activation after chilling and forcing dormant apple trees. J. Amer. Soc. Hort. Sci. 115:809-814. 